\title{
Thinking Through Improvisation: Do General Improvisation Studies Belong in a Liberal Arts Curriculum?
}

\section{Dominic Poccia}

It is an almost universal tenet of liberal arts education that critical and creative thinking constitute essential elements of the undergraduate curriculum (LEAP). Improvisation combines these two elements while demanding the rapid processing of ideas. Unfortunately, improvisation as a subject of inquiry in the liberal arts curriculum is typically restricted to individual departments, usually a subset of the arts or psychology, rather than more widely incorporated across disciplines. Most strikingly, improvisation is rarely used as the subject of freestanding general courses.

In this essay, I will argue that educators should recognize the importance of improvisational thinking across the entire liberal arts curriculum and incorporate it in its full interdisciplinary (Crosby) and multicultural (Nettl, "Thoughts on Improvisation" and "Landmarks in the Study of Improvisation"; Hull) contexts. Indeed, improvisational expertise might even be viewed as comparable to proficiency in expository writing or quantitative reasoning-skills which are often seen as foundational for critical and creative thinkers, including well-educated liberal arts students.

Improvisation and creative thinking are tightly linked (Sawyer, "Improvisation and the Creative Process"; Hallam and Ingold; Sarath) and cross virtually all disciplinary boundaries. By exploring their general properties and their relationships early in the liberal arts curriculum, we can approach the link between improvisation and critical thinking in an explicit and critical way, allowing students to experience a wide range of disciplinary integration in both their academic pursuits and their daily extracurricular lives. This approach will also prepare students for a rapidly changing social and professional world after they graduate.

In this essay, I define improvisation as any activity which generates a product in real time in which editing takes place virtually simultaneously with production. It may take many forms: ad hoc solutions to emergencies, quick witticisms, scientific brainstorming, or the creation of deeply expressive art. Successful improvisation most often involves considerable preparation to supply the raw material from which it flows. It benefits from the practice of letting ideas develop without premature criticism while simultaneously organizing thought in a productive or aesthetically effective manner.

Improvisational (i.e. in-the-moment) and non-improvisational (i.e. edited) modes can be seen as boundary conditions encompassing a graded balance that can be adjusted in problem solving, idea generation, communication, and in many other ways that we use our minds (Pressing; Dixon; Calvin, "Evolving Improvisational Intelligence"). Improvisation can serve as a major supplement to the kinds of activities students are typically encouraged to engage in, such as continual re-editing of papers with iterative refinement of ideas, critical reading of texts, or standardized examinations requiring mastery of factual material. All of these undertakings are of great value, but the ability to think on one's feet, edit in real time, and rapidly explore raw ideas that subsequently may be re-edited to provide a rich reservoir of innovation in all academic fields and is the basis of creative ideation. Therefore, some degree of proficiency in improvisation should be a crucial element in the repertoire of skills we expect of our liberal arts students. 
Because improvisation can be critically examined, practiced, and developed within nearly any context, improvisational studies are quickly becoming a vigorous area of scholarship (Lewis; Heble). The diversity of academic disciplines to which improvisation applies and which can be used to illustrate how it functions is extraordinary, ranging from literature, philosophy, theology, music, dance, cinema and visual arts to urban planning, architecture, psychology, neuroscience and computer science. Increased recognition of the importance of improvisation and creative thinking in post-graduate activities from science and medicine (Bernstein; Brett-MacLean; Watson; Hentoff; Haidet; Erkkilä) to teaching, architecture and business (Berk; Barrett; Hamdi; Ingram; Sarath) provides an additional rationale for a central role of improvisational studies in the preparation of the undergraduate liberal arts student.

Although there is ample room for integration of improvisational ideas in many specialized courses, where specific skills can be honed to a high degree, the introduction of improvisation as a subject worthy of general study early in the curriculum has the advantage of promoting it as a pliable tool that students can experience, learn, and apply to specific courses throughout their university careers. I believe that an in-class, explicit recognition of the power of improvisational thinking and deliberate examination of its origins, requisites, and techniques can take hold over time in students' minds and generate thinkers who are not only more critically adept, but also more likely to be innovative, creative, and inclined towards reasonable risk and exploration. Finding a central place for the general study of improvisation in the curriculum is a most natural way to engage young minds, unite the (often ignored) link between doing and thinking, and achieve a vibrant symbiosis of critical and creative thinking. Students will apply these skills not only within the academy, but also in the mercurial world they will experience when they graduate.

I consider in this paper the justification for wide-ranging interdisciplinary improvisation courses in the liberal arts curriculum, some criteria for the selection and teaching of their content, and anticipated barriers to their adoption. I outline an example of such a course, the First Year Seminar entitled Thinking Through Improvisation offered at Amherst College by my colleague and I since 1997.

\section{Some Tenets of Liberal Arts Education}

What constitutes a liberal arts education remains an ever-evolving debate, one which is further complicated when attempting to prioritize the importance of specific skills, tasks, and disciplines. However, in modern practice there is a common consensus concerning curricular breadth, and while the liberal arts curriculum may include highly specialized studies, it typically encompasses examination and integration of elements common to many areas of thought and inquiry such as critical thinking, close reading, problem solving, writing, quantitative thinking, creative thinking, art and aesthetic values, interdisciplinarity, communication skills, adaptability, respect for learning and free inquiry, multiculturalism and sometimes teamwork, ethics and responsibility to society (LEAP; Kagan).

In the United States, liberal arts are taught through Schools of Arts and Sciences at most universities, as well as in some specialized schools and in liberal arts-focused colleges. Liberal arts studies are often seen as alternatives to more specialized or technical education, but should, I believe, also permeate and inform the latter. It is becoming increasingly clear that the changing nature of employment, as well as the likelihood that most college-educated people will have many different jobs over their lifetimes, makes liberal arts education and its emphasis on problem-solving, teamwork, thinking "outside the box" and thinking "on one's feet" (Symonds; McNutt) increasingly valuable. 
Employers, graduate schools and professional schools have recognized the growing importance of creativity and improvisation, as more routine tasks are either insufficient or taken over by computers or robots. Many prefer to provide the most specialized training to their employees or students who have acquired a solid background in the liberal arts. Applications of improvisational approaches range from business organization and consultancy (Weick; Hadida; Laver; Barrett) to architecture (Hamdi; Brown) to medical and dental school teaching and practice (Brett-MacLean; Haidet; Erkkilä; Watson).

Liberal arts education is seeing a recalibration in the $21^{\text {st }}$ century (LEAP). Some of the impetus for this is driven by our increasingly diverse student bodies, along with the recognition that students arrive with very different ways of learning fueled-in large part-by the overwhelming presence of the internet. However, the diversity of students and shift in learning styles does not change youthful inclinations such as spontaneity and risk-taking, nor does it change the caution and concerns of most students, especially concerning grades and self-presentation. Notably, these inclinations are naturally addressed in discussing and practicing improvisation.

Improvisation can build trust and cultivate healthy approaches to risk-taking, fostering personal growth that not only makes improvising students better scholars, but also more collaborative and resilient people.

In the Teagle Foundation Report: Creative and Critical Thinking: Accessing the Foundations of a Liberal Arts Education, the faculty of five distinguished liberal arts institutions grappled with the definitions and processes of two foundations of thinking they believed were most important for their students to master (The Five Colleges of Ohio). They emphasized the ideals of: Elements of Argumentation (explanation, analysis, evaluation, interpretation and logic, domain and disciplinary knowledge, synthesis and connections, abstract thinking and complexity of thought); Idea Generation (fluency and flexibility, completeness/coherence, elegance and divergent thinking); and Novelty (germinal, original and transformational; engagement and risk-taking). Few liberal arts faculty members, I think, would disagree about the value of these ideals. Curiously, however, the term improvisation never appears in the Teagle report, although it is hard to imagine practicing improvisers in any discipline taking issue with most of these ideals as illustrations of their own methods or goals.

Faculty at liberal arts institutions constantly discuss curriculum and how we might improve pedagogically, but improvisation typically gets little attention by teachers or students as a general curricular issue (Berk). Is it because improvisation as a subject of study and practice is usually limited to theater or music departments, and even there can be marginalized or stereotyped? Or is it because improvisation is not considered a critical activity? One wonders why students at the five institutions ranked "critical thinking" to be most necessary in the Natural Sciences followed in decreasing order by Social Sciences, Humanities, and the Fine Arts, and then classified "creative thinking" in the reverse order, topping the latter ranking with "extracurricular activities"! And why were "interdisciplinary work" and "active learning" considered by the Report to be the most relevant activities with which to engage students, but with no mention of improvisation? I will address some of these questions below and suggest how general improvisation skills can contribute to achieving these ideals.

\section{Teaching General Improvisation in the Liberal Arts Curriculum}

\section{A First-Year Seminar}

My initial interest in examining general aspects of improvisation in a university course stemmed from my roles as teacher, research scientist, and musical improviser. At first glance, teaching a 
general course in improvisation seemed a bit daunting. However, I learned that there are many diverse and creative ways to introduce general improvisational studies into the curriculum and many possible ways to organize course material while retaining the basic tenets of liberal arts education and emphasizing both critical and creative thinking. I will describe below how my colleague, Prof. Andy Jaffe, and I initiated this in 1997 in a course which has been taught continually for over 20 years as part pf the Amherst College First-Year Seminar Series. The topic of each Seminar in this series is guided by the instructors' interests. All students are required to take one of the Seminars in their first semester. The Seminars are designed to deal with critical interpretation and reading, active learning, and writing in small discussion-based classes, but are not usually related in subject matter. I offer my experience with this course not as a definitive model but rather as a prototype, an illustration of one way in which a beginning course in general improvisation can be constructed in accordance with the previously stated liberal arts goals. I also outline the rationale and expectations for our various activities.

The name Thinking Through Improvisation was deliberately chosen to imply two meanings: 1) carefully examining all that improvisation encompasses and how it is practiced, and 2) using improvisation to generate ideas or performances. We thus sought to impart an understanding of what constitutes successful improvisation and then to put it into practice in a reiterative process of performance and critical assessment using as wide a range of disciplines as is feasible in one semester. Mastery of any specific disciplinary area of improvisation was, of course, not our goal in an introductory course.

Throughout these seminars, several liberal arts objectives are naturally incorporated into the subject matter. As a class, we examine the concepts of improvisation (critical reflection), observe improvisers in action (analysis), perform improvisations to better understand them (problem solving, communication), take a multidisciplinary perspective (general knowledge, synthesis of knowledge), take a multicultural perspective (general knowledge), and explore the relationship between creativity and improvisation (intellectual skills). Students are asked to read, discuss, and write critically. They are asked to perform simple improvisations, as well as witness more complex ones and reflect on them. We try to make it both serious and fun, overcoming inhibitions including fear of judgment that stymie group interactions. We also speculate on the origins and mechanisms of improvisational acts and explore current understanding of the processes of improvisation both intuitively and scientifically.

\section{Reading, Discussion, and Critical Thinking about Improvisation}

Much of the Seminar is devoted to reading two texts and several articles which are discussed in class and analyzed in short essays. The small class size (14 or 15 students) facilitates dialogue. To encourage both the more timid students and those who did not take the reading seriously to actively participate in discussion, I ask students to prepare one or two questions on the day's reading to ask of their colleagues during class. I choose the names of the questioners and first responders randomly, often by literally drawing names from a hat. If a student has not thought about the text, it quickly becomes apparent. Shy students are still expected to formulate answers, but I believe feel less pressure being asked by a classmate rather than an instructor. If the question leads to an interesting discussion, other students or I will enter the conversation. These group discussions stimulate the examination of ideas from multiple perspectives. The exercise serves to clarify the readings and elicit different interpretations of ideas from the texts. Of course, these discussions are themselves exercises in improvisation as are all good conversations (Sawyer, Creating Conversations...). Student evaluations frequently note enthusiasm about the group discussions as opportunities to both learn from and help their classmates to express their individuality. 
Our two texts are Free Play: Improvisation in Life and Art by Stephen Nachmanovitch and Book 1 of The Act of Creation by Arthur Koestler. Since this is an introductory course, these texts were chosen for their generality, accessibility, breadth, and ability to connect the two main themes of the course, improvisation and creativity, in order to help organize and define what each of these terms might mean.

Nachmanovitch introduces the students to general ideas about improvisation and its relationship to quality of life. He emphasizes several important aspects of improvisation, dispelling along the way several misconceptions. Drawing primarily from the humanities, he considers: 1) the origins of inspiration, flow, play, and surrender; 2) the hard work and practice that goes into successful improvisation and the embedding of subroutines into muscle memory to draw upon seamlessly during execution; 3 ) the power of mistakes and their incorporation into the discoveries of improvised thought; 4 ) the role of limits in stimulating improvisation; 5 ) the satisfaction of group improvisation and playing together; 6 ) obstacles to successful improvisation including self-doubt and fear, procrastination and hesitation, premature judgement, and the antidotes of patience and surrender to allow improvisational flow; 7) the joy of accomplishment and the thrill of in-themoment discovery; and 8) the importance of quality and life values of play and discovery. Nachmanovitch's examples include a multicultural dimension, often drawn from Asian sources such as Buddhist, Chinese or Persian philosophy, in addition to Western writings. As the course unfolds, our class returns to him again and again, applying his ideas to the wide range of specific endeavors we are exploring to see how they function in different contexts.

In Book 1 of The Act of Creation, Koestler discusses novelty, invention, and sources of the creative life. He balances discussions of creativity in the sciences and the arts-and humour!using an extended metaphor of the intersection of two or more self-consistent matrices (frames of references, universes of discourse with their own rules). When these previously incompatible matrices are brought together in the act of creation, they interact to create novelty. In humour, the matrices abruptly collide, when one "sees" the joke, to cause a mental leap from one to the other that is released as laughter-for instance, in the surprise of a well-delivered punchline. In science, a new synthesis is achieved by resolving the matrices to create a new paradigm, as exemplified by Darwin's synthesis of evolution and survival of the fittest in the concept of natural selection or Kepler's synthesis of physics and astronomy to describe the orbit of the planets as elliptical rather than circular. In art, the juxtaposition of the matrices creates a contemplative space recognizing paradox, tragedy or beauty, allowing exploration of the matrices to reveal many facets of a subject without the need to resolve to a single explanation. Koestler emphasizes dreams and dream-like states and the role of the subconscious in idea generation. His sources are largely Western European. His text is important in stimulating students to consider the breath of human inquiry, especially in fields with which they have the least experience, and to understand the commonalities of creative discovery in diverse fields.

In addition to these primary texts, sets of short scholarly papers are assigned addressing three themes: the relationship between improvisation and creativity (Sawyer, "Improvisation and the Creative Process"; Kraft; Moyer), the evolution of improvisational intelligence (Calvin, "The Emergence of Intelligence," "A Stone's Throw"; Dicke) and the neurobiology of improvisation (Limb; Liu). These short works ranging from Scientific American articles to original research papers are the basis of class discussions which are presented by small teams of students. These presentations are followed by clarification questions posed by classmates which, if built upon thorough preparation, prompt well improvised responses.

\section{Writing about Improvisation}


In addition to critically summarizing the scholarly papers in 4-page essays, a 15-page term paper is required on a subject of the student's choice in which improvisation plays a major role. This capstone paper serves to consolidate what students have learned about improvisation and to extend their knowledge to a specific area of behavior, investigation, or performance. An inclusive and diverse set of references is provided to serve as a guide for the subject matter, but students are encouraged to be inventive in their choice of topic. Useful student suggestions from course evaluations have led to our incorporation of more time to work on the term papers and more guidance on making the leap from writing shorter papers. We have enlisted experts available at the College Writing Center and Library to guide students in organizing short and long papers and methodologies for research preparation for term papers. Although most of these skills are not improvisational, they help to satisfy the common goals of all First Year Seminars of developing writing and critical thinking skills.

An important aspect of the research paper is encouraging students to propose novel subjects in specific areas already of interest to them which, in turn, encourages them to seek out research sources with greater enthusiasm. Since improvisation lends itself to a wide range of subjects, it is usually not difficult for students to come up with suitable topics. These have ranged from the fairly obvious or general (Mistakes and Improvisation, Stress and Its Effects on the Ability to Improvise, Improvisation in Wilderness Survival, Improvisation and Conversation, Improvisation in Basketball) to the more inventive or specific (Improvisation in Crisis Management, Creative Dating: Improvisation in Forming Relationships, Political Discourse and Debate as a Forum for Improvisation, Doctors in Wartime, Flash Mobs, Bedouin Poetry: The Decline of Improvisation, Flavors of Spontaneity: Improvisation in Cooking).

Additional required writing includes analyses of two live improvisational performances students attend during the semester-one musical, one theatrical or comedic-which promote attentive listening. A short self-critique of their own in-class performances is also mandatory in order to deepen their understanding of some of the practical issues surrounding successful improvisation. Except for the self-critiques, all papers-along with class participation-serve as criteria for grading.

\section{Active Learning}

Active learning and interdisciplinarity were the two most important recommendations of the Teagle report to encourage critical and creative thinking. The increasing popularity of active learning techniques derives from the belief that students learn best when directly engaged in the learning process rather than passively listening to lectures or watching examples given by others. It has appeal to contemporary students who usually enjoy working in collaboration with their colleagues. Engagement may consist of discussion and problem solving in groups.

Traditionally, such learning is associated with seminar courses or science laboratories and is a mainstay of performance arts courses. Quantifying the outcomes of active learning is still a subject of active investigation with variable accounts of its effectiveness and long-term success. While it is straightforward to compare achievements on standardized tests of active learners with control groups (Bossaer; Connell; Freeman), it is more difficult to assess effects of this learning style on long-term learning and problem solving (Prince).

In addition to class discussions, active learning in the Thinking Through Improvisation seminar involves student performances with guests and in-class improvisations (group or solo). Many professional improvisers learn their craft by example, either through apprenticeship with mentors or by listening to or observing improvised works. The course has benefited greatly from several guest lecturers and performers. I have found it relatively easy to recruit seven or eight 
local experts with relevant talents and interests to perform in-class improvisations or to analyze an area related to previous class discussions. Significantly, several guests perform improvisations with the students. Student improvisations with visitors ease them into performance with expert guidance and without the pressures of being on stage alone or being expected to execute highly polished performances. The visitors are invariably enthusiastic about returning in subsequent years.

Chosen carefully, presenters also bring a multicultural perspective to the class. Student collaboration in presentations has involved storytelling, dance, cooking, mime, and improvisational games. Outside lecturers have discussed German experimental dance companies, African art, Chinese calligraphy, improvised balloon sculpture, Indian music, jazz, rap, and the psychology of creativity.

Much like Berliner's interviews of jazz musicians in Thinking in Jazz, students ask the guests how they think when they improvise, how they learned to improvise, and what they consider the most important skills in their areas of expertise. This occurs not only in class but at lunches following class with the presenters and small groups of students. Several presenters have remarked on how their interactions with the students have stimulated their re-thinking of how they apply improvisational techniques.

\section{Dealing with Barriers to Improving Improvisational Skills}

Early in the course, students learn from Nachmanovitch that fear is a major obstacle to good improvisation. Defenses take the form of "playing it safe," not participating fully in class, not losing oneself ("surrendering") in the improvisational exercises with guests or classmates, or the choice of routine paper topics. Major barriers include fear of appearing foolish, shyness, desire to perform overly polished or error-free improvisations, lack of trust, and awareness of being graded. Similar fears are common in all courses, but they are particularly detrimental to the improvisational mind, especially for public performances.

By alleviating several of these feelings early in the course, many of these barriers are minimized. In order to relieve some anxiety, I do not grade improvisational in-class performances. Instead, in asking for written self-evaluations, I encourage students to reflect on what they thought worked and what didn't. For beginning and seasoned veteran improvisers alike, this exercise can be illuminating. Significantly, such reflection can be linked to the scientific analyses of the improvising mind examined in class as well as to ideas shared by our visitors.

The in-class performances near the end of the semester are a highlight of the course. Sometimes they take the form of music or dance presentations, videos, or visual art constructions. Most often they involve verbal improvisations: skits, debates, or storytelling with audience suggestions for themes. Especially in group performance, students need to develop trust in their classmates. Trust is greatly facilitated by formation of First-Year Seminar cohorts arranged by the College during freshman orientation prior to the beginning of the semester. It has proven very useful to start the outside presentations with a skilled practitioner of improvisation games using large doses of humour to "break the ice." Once trust is established, the road to practicing improvisation is more easily facilitated and most students become surprisingly uninhibited. Unexpected discoveries during performances when "letting go" are the best antidotes to the fear of risk-taking. 
It is most important for the students to discuss the self-analysis papers they have submitted. I have found it best to do this one-on-one with them even if they performed a group improvisation. Since their classmates are not present and their improvisations are not graded, candor in their analyses is facilitated thus opening avenues to explore the concepts of quality or success in improvising. The kinds of questions that arise include students' sources of insecurity, the importance of preparation, planning for form without over-planning, accepting limits or rules, audience reactions, and moments of self-discovery. Differences in expectation and execution lead to a personal understanding of many concepts dealt with more abstractly in class.

\section{The Science of Thinking in the Moment}

As noted, several scholarly papers required in the course involve rather detailed readings of contemporary neuroscience research literature. This is unusual for a first semester course and a challenge for students, especially for those with limited scientific background or interest. However, there are several reasons to include this material: to re-emphasize the breadth and commonalities of scientific and artistic inquiry illustrated by Koestler; to compare concepts arising from controlled experiments that address current understanding of how brains of improvisers function with the more subjective impressions of the experience of improvisation; to understand that science, in its creative mode, can also involve improvisation in formulating hypotheses; and to unite students with diverse interests in trying to bridge gaps in their backgrounds in a mutual effort to understand some new concepts from neuroscience. Students report that, with appropriate guidance through the jargon of the research papers, they are able to see how a scientific approach can aid our understanding of what happens during improvisational thinking.

To deepen our understanding of the processes and possible origins of improvisational ability, we include scientific interpretations in the course. Science has been used as an analytical tool to explore mental activities that occur during improvisation and creative tasks. Conversely, improvisation has been put to practical use in the sciences; for example, it has been used to improve communication by scientists to the public (Alda) and to stimulate creative problem solving in biomedicine (Watson; Haidet).

Science should be an essential part of a modern liberal arts education (Crane). It can be quite naturally incorporated into a general course on improvisation. Although it is much more typical to use the arts as a source for the discussion and practice of improvisation, there are many ways of introducing science to all students, including non-scientifically inclined students. For example, one can incorporate speculations on the origins and evolution of improvisational intelligence (Calvin, "The Emergence of Intelligence;" Rothenberg) or discuss attempts to relate wave equations to creative leaps of imagination or to incorporate improvisation into string theory in physics (Alexander). Additionally, psychological literature is rife with books and papers on improvisation and the concept of flow (Csíkszentmihályi)—a concept which still searches for neural mechanisms.

Instructors who might feel limited in dealing with scientific material in any particular area might benefit from choosing different types of articles, using explanations of research from the popular press, or supplementing the class with expertise from invited visitors. But I believe a full treatment of the practice of improvisation would be incomplete without addressing how the brain functions when thinking improvisationally.

Using novel brain imaging techniques to unravel brain functioning, we are now making our way towards reasonable hypotheses about the improvising mind. Discussion of the subject, 
however, requires students to develop some understanding of basic scientific approaches from psychology, evolution and neurophysiology. One of the most fertile, though still embryonic, areas of scientific investigation derives from recent applications of functional magnetic resonance imaging (fMRI) and related techniques, which can constructively complement neuropsychological approaches in the understanding of brain function during improvisation and creativity (McPherson; Abraham). Experimental subjects are imaged when presented with improvisational or creative tasks and compared to control subjects. By recording changes in blood flow in the brain, correlations can be made about which regions are activated or deactivated. ${ }^{1}$

It is encouraging that many $\mathrm{fMRI}$, EEG, and computer modeling studies continue to appear addressing improvisation and creativity in poetry, music and dance (Berkowitz, "ExpertiseRelated Deactivation of the Right Temporoparietal Junction during Musical Improvisation"; Fink; Liu; Bengtsson; Saggar; Beaty; Magerko; Fuller; see endnote for complete explanation) and even possible contrasts in artistic and scientific modes (Shi). Such studies remind us of our subjective opinion that the brain is working differently in improvisational and non-improvisational activities or during emergencies or other situations that require split second timing (Nakata). For example, seasoned jazz musicians may avoid reading chord symbols while soloing, a practice which can inhibit careful listening and focusing on the extended solo form (Berliner). Skilled baseball players may avoid over commitment to what they anticipate as the next pitch. Or as Yogi Berra was purported to have said, "You can't think and hit at the same time."

Attaining the state of flow in art or being in the zone in sports may not be so different during that time when all the deliberate training pays off in an apparently miraculous performance that can delight both the observer and the performer. The scientific studies hint at how the brain reassigns thought processes but leave open the question of how in practice such reassignments are facilitated by experience (Dixon; Chrysikou). Trying to understand improvisation from both the artist's and the scientist's perspective brings our students back to Koestler who realized that their goals might be different, but their innovative thinking might be generated quite similarly. We will need to combine as many approaches as possible to advance our understanding of the largely unconscious processes of improvisation and creative flow.

\section{Objections and Concerns}

General improvisation studies, especially beyond the introductory, are at present well outside the curricular consciousness of most liberal arts professors and administrators. That impediment would have to be overcome by an ongoing, active dialogue and sustained advocacy. There will be many objections, including the ideas that improvisation is not a serious subject; it does not constitute an academic field; it does not fit into standard disciplinary boundaries; departmental staffing needs are more important; most professors don't know enough about improvisation to teach it or do it; it can't be implemented for all students; we all improvise so we really don't need to teach it; and we do not have the resources to devote to it.

However, we can begin to formulate responses to some of these objections. First, it is probably best to think of learning improvisational skills as developing complementary techniques of effective, critical thinking in the liberal arts, just as we value expository writing, quantitative skills, and hypothesis formulation and testing as important tools. This would position improvisational abilities as essential to effective thinking and applicable to at least as wide a range of disciplines as any other general skill. 
Improvisation as a subject area might become as much of a discipline as poetry, calculus, or abnormal psychology given the increased scholarly attention being paid to it, but this seems rather unlikely. It may be that most professors have little overt experience with improvisation or would not teach it for fear of inadequacy or even ridicule from colleagues in their own subdisciplines. Here, one might argue that a cadre of improvisors could be recruited to complement in-house faculty, perhaps populating an improvisation or creativity center akin to those often found for writing or quantitative skills. Alternatively, distribution requirements might encourage regular faculty participation outside of departmental boundaries. In practice, we have not found it difficult to recruit supplementary personnel as presenters to class, either from current faculty who cannot or do not wish to participate in a full course in improvisation or from the active communities surrounding the academy.

Even without a radical restructuring of curricula and requirements, we could recognize that everyone improvises, although certainly some of us are either more skilled at it or have more of an interest in it. We could recognize that improvisation can be taught and learned so that instructors as well as their students can get better at it (Heble; Pinho). The rewards become apparent in agility of mind and the pleasure of improvising well in whatever field in which we choose to practice. For me, one of the most satisfying and surprising aspects of teaching general improvisation has been the feedback from colleagues who, after having the experience of presenting in the course, tell me how it had influenced the way they viewed their own teaching or scholarly work. It has changed my own approach to the classroom-in lecturing and active learning situations-and to the laboratory, in the execution of experiments, and hypothesis generation.

I am not so naïve as to think that a requirement for even one general improvisation course would be simple for an academic institution to put into practice. But one can make a convincing link to creative thinking and to the practical uses of creative and improvisational skills in industry or business (Ingram), medicine (Hoffmann-Longtin), law (Piper), teaching (Berk) and most professions that our students move on to. And aside from enhancing future employment prospects, the practice of improvisation can add immensely to the enjoyment and quality of the life well-lived: full of curiosity, self-discovery and accomplishment that we espouse for our students. My experience is not that students or other community members need to be convinced of the benefits of such courses. They are invariably enthusiastic. But the academic community is difficult to change, and change would have to begin with a cohort of colleagues intensely committed to advocating for improvisation as a cornerstone of liberal arts education.

Several issues will require further exploration for courses beyond the introductory level. How can we most effectively incorporate improvisational studies into curricula based on departmental disciplines? How much do we need to be explicit about which activities are improvisational and why they are important? How do we encourage risk in a grade-based system and how do we evaluate student improvisations? How do we ensure that students do the preparatory work for good improvisation and mastery of a discipline? By what means can we be culturally sensitive to the various meanings and practices of improvisation? How can we maintain a small class size more conducive to interactions?

In any event, I believe the best place to start is in the first semester, when students are most malleable and open to ideas beyond their future majors, immediate interests, or previous inclinations, as well as when they are establishing new social structures and exploring what the academy has to offer them.

\section{Summary and Conclusions}


My teaching of general improvisation has convinced me of several things. First, it has taught me that courses in general improvisation have the potential to integrate many areas of study in the liberal arts curriculum. Second, that virtually all people can (and do) improvise; it is an essential human activity, perhaps selected for its survival value in dealing with emergencies or unexpected opportunities. It is an activity we can both analyze and practice in order to improve. My teaching has also taught me how improvisation requires a freedom of thought similar to what occurs in play, a freedom which can be highly or loosely structured and uses the power of limits and errors as a spur to creativity. Group improvisation prizes acceptance of all offers and constructive extension of them, a habit as valuable in brainstorming sessions (Gerber) as in improvised arts (Montanaro; Johnstone; Berliner).

I have also learned how complex improvisation requires intellectual rigor and a large amount of preparation. Many executable subroutines must be readily accessible to the improviser to facilitate improvised constructs and rapidly generate structure, form and content in addition to style. These subroutines are acquired by practice and direct apprenticeship and by finding ways to allow the unconscious brain and "muscle memory" to rise to the surface. Improvisation differs in its creative aspects from non-improvisational activities only in requiring execution in the moment, when ideas are edited virtually simultaneously with their act of creation. Risk is valued since mistakes can be used as raw material for creative flow while requiring immediate incorporation into the process. The process is as valuable as the final product, and often is the final product.

Should we be able to introduce a requirement or at least a widely available opportunity for general improvisation studies, not tied to a major but intricately and deeply linked to the liberal arts education we embrace, it would have profound effects on the type of educated individuals we send into the world to begin the next steps of their education. And as an added benefit, I believe we will nourish and retain enthusiastic gratified professors who get to experience the eclectic joys of teaching, studying, and practicing general improvisation in the classroom. It can be transformational.

\section{Acknowledgements}

I am deeply indebted to my colleague and great friend Prof. Andy Jaffe, a gifted improviser and teacher, with whom I first developed the ideas and structure of Thinking Through Improvisation and who co-taught it with me in its first three years. Also, to my more recent colleague Prof. Darryl Harper, a sensitive and deep thinker and musician, for many discussions and ideas about the organization and future of the course and who is continuing to teach it. And finally to all the talented presenters who have contributed to the class since its inception.

\section{Notes}

${ }^{1}$ An increasing number of scientific papers are devoted to fMRI studies of improvisation and creativity (Berkowitz and Ansari, "Generation of Novel Motor Sequences"; Berkowitz and Ansari, "Expertise-Related Deactivation"; Dixon et al.; Limb and Braun; Liu, Chow, et al.; Saggar et al.; Nakata et al.; McPherson, Barrett, et al.; Liu, Erkkinen, et al.; Fink, Grabner, et al.; Erhard et al.; Ellamil et al.; Brown and Parsons; Bengtsson et al.).

A pioneering study by Limb and Braun using fMRI on skilled improvising musicians found that, in these subjects, areas of the prefrontal cortex that normally suppress self-monitoring and volitional control were deactivated while regions that control autobiographical, self-expressive 
tasks, rule maintenance, and musical execution and organization were activated. This early study can be interpreted to reinforce reports by performing improvisers, including athletes, of the feeling of "flow" or being "in the zone," real-time monitoring of form, and intuitive responses. Or as Limb and Braun put it, "innovative, internally motivated production of novel material (at once rule based and highly structured) that can apparently occur outside of conscious awareness and beyond volitional control."

Other workers came to similar conclusions studying freestyle rappers who add an improvised verbal dimension to musical improvisation (Liu, Chow, et al.; Hisama). Liu, Chow et al. concluded that the regions that regulate motivation, incentive, intentionality, and drive and act between intention and action while synthesizing information and encoding goals is modulated. They suggested that these regions which impose executive function (loosely defined as the way the brain controls the processes of knowledge acquisition) before the motor system acts, may be bypassed during improvisation. Routed to other behavior-orchestrating areas, this may facilitate flexibility and exploratory behavior, releasing regions of sensory processing that result in subjective experience, immersion and even loss of self-consciousness.

Interestingly, the self-generated, stimulus-independent behavior normally initiates before the subject consciously experiences the intention to act, so that intention appears to come from outside. Perhaps this is what we subjectively experience as inspiration and freedom from excessive inhibition. It does not address the question of how a balance can be achieved between self-generated stimulus-independent behavior and the need to incorporate at virtually the same time environmental input from, for example, one's improvising partners during a group improvisation. But this type of study, I believe, bridges the science of behavior and the psychology of performance creativity with the more subjective feelings of emotion and surrender (such as states of transcendence discussed by Nachmanovitch). This gives students much to ponder as they try to understand how we think while improvising.

\section{Works Cited}

Abraham, Anna. "The Neuropsychology of Creativity." Current Opinion in Behavioral Sciences, vol. 27, 2019, pp. 71-76.

Alda, A. If I Understood You, Would I Have This Look on My Face?: My Adventures in the Art and Science of Relating and Communicating. New York, Random House, 2017.

Alexander, S. The Jazz of Physics. New York, Basic Books, 2016.

Barrett, F. J. "Coda: Creativity and Improvisation in Jazz and Organizations: Implications for Organizational Learning." Organization Science, vol. 9, 1998, pp. 605-622.

Beaty, R. E. "The Neuroscience of Musical Improvisation." Neuroscience and Biobehavioral Reviews, vol. 51, 2015, pp. 108-117.

Bengtsson, S. L., et al. "Cortical Regions Involved in the Generation of Musical Structures during Improvisation in Pianists." Journal of Cognitive Neuroscience, vol. 19, 2007, pp. 830-842.

Berk, R. A., and R. H. Trieber. "Whose Classroom Is It, Anyway? Improvisation as a Teaching Tool." Journal on Excellence in College Teaching, vol. 20, 2009, pp. 29-60. 
Berkowitz, A. L., and D. Ansari. "Expertise-Related Deactivation of the Right Temporoparietal Junction during Musical Improvisation." Neurolmage, vol. 49, 2010, pp. 712-19.

---. "Generation of Novel Motor Sequences: The Neural Correlates of Musical Improvisation." Neurolmage, vol. 41, 2008, pp. 535-43.

Berliner, P. Thinking in Jazz The Infinite Art of Improvisation. Chicago, University of Chicago Press, 1994.

Bernstein, R. “Communication: Spontaneous Scientists." Nature, vol. 505, 2014, pp. 121-123.

Bossaer, J. B., et al. "Student Performance in a Pharmacotherapy Oncology Module Before and After Flipping the Classroom." American Journal Pharmaceutical Education, vol. 80, 2016, pp. 3-8.

Brett-MacLean, P., et al. "Exploring Professionalism in Undergraduate Medical and Dental Education through Forum Theatre." Journal for Learning Through the Arts, vol. 8, 2012, pp. 1-8.

Brown, D. P. Noise Orders Jazz, Improvision, and Architecture. Minneapolis \& London, University of Minnesota Press, 2005.

Brown, S., and L. Parsons. "The Neuroscience of Dance." Scientific American Magazine, July, 2008, pp. 78-83.

Calvin, W. H. "A Stone's Throw and Its Launch Window: Timing Precision and Its Implications for Language and Hominid Brains." Journal of Theoretical Biology, vol. 104, 1983, pp. 121-135.

---. "Evolving Improvisational Intelligence." Proc. International Fed. Science Editors, unpublished, 1997, williamcalvin.com/1990s/1997SciEds.htm.

---. "The Emergence of Intelligence." Scientific American, vol. 271, 1994, pp. 100-107.

Chrysikou, Evangelia G. "Creativity in and out of (Cognitive) Control." Current Opinion in Behavioral Sciences, vol. 27, 2019, pp. 94-99.

Connell, G. L., et al. "Increasing the Use of Student-Centered Pedagogies from Moderate to High Improves Student Learning and Attitudes about Biology." CBE-Life Sciences Education, vol. 15, 2016, pp. 1-15.

Crane, M., and T. Chiles. "Why the Liberal Arts Need the Sciences (and Vice Versa)." The Chronicle of Higher Education, 13 November 2011, www.chronicle.com/article/Why-theLiberal-Arts-Need-the/129762/.

Crosby, D. A., and R. G. Williams. "Creativity Problem Solving in Physics, Philosophy and Painting: Three Case Studies." In Creativity and the Imgination: Case Studies from the Classical to the Twentieth Century, edited by A. Amsler, University of Delaware Press, 1987, pp. 168-214. 
Csíkszentmihályi, M. Flow: The Psychology of Optimal Experience. New York, Harper \& Row, 1990.

Dicke, U., and G. Roth. "Intelligence Evolved." Scientific American Mind, vol. 19, 2009, pp. 7077.

Dixon, M. L., et al. "A Framework for Understanding the Relationship between Externally and Internally Directed Cognition." Neuropsychologia, vol. 62, 2014, pp. 1-10.

Ellamil, M., et al. "Evaluative and Generative Modes of Thought during the Creative Process." Neurolmage, vol. 59, 2012, pp. 1783-94.

Erhard, K., et al. "Professional Training in Creative Writing Is Associated with Enhanced FrontoStriatal Activity in a Literary Text Continuation Task." Neurolmage, vol. 100, 2014, pp. 15-23.

Erkkilä, J., et al. "The Effect of Improvisational Music Therapy on the Treatment of Depression: Protocol for a Randomised Controlled Trial." BMC Psychiatry, vol. 8, 2008, pp. 1-9.

Fink, A., B. Graif, et al. "Brain Correlates Underlying Creative Thinking: EEG Alpha Activity in Professional vs. Novice Dancers." Neurolmage, vol. 46, 2009, pp. 854-62.

Fink, A., R. H. Grabner, et al. "Enhancing Creativity by Means of Cognitive Stimulation: Evidence from an FMRI Study." Neurolmage, vol. 52, 2010, pp. 1687-95.

Freeman, S., et al. "Active Learning Increases Student Performance in Science, Engineering, and Mathematics." Proceedings of the National Academy of Sciences of the United States, vol. 111, 2014, pp. 8410-15.

Fuller, D., and B. Magerko. "Shared Mental Models in Improvisational Theatre." Proceedings of the 3rd Workshop on Intelligent Narrative Technologies at the Foundations of Digital Games, 2010.

Gerber, E. "Using Improvisation to Enhance the Effectiveness of Brainstorming." Conference on Human Factors in Computing Systems, 2009, pp. 97-104.

Hadida, A., and W. Tarvainen. "Organizational Improvisation: A Consolidating Review and Framework." International Journal of Management Reviews, vol. 17, 2015, pp. 437-459.

Haidet, P. "Jazz and the 'Art' of Medicine: Improvisation in the Medical Encounter." Annals Of Family Medicine, vol. 5, 2007, pp. 164-69.

Hallam, E., and T. Ingold. Creativity and Cultural Improvisation. Berg, 2007.

Hamdi, N. "Architecture, Improvisation and the Energy of Place." The Resourceful Architect, 2010, architecture.brookes.ac.uk/research/cendep/media/The Resourceful Architect_RSA (Nabeel Hamdi).pdf.

Heble, Ajay and Mark Laver. Improvisation and Music Education : Beyond the Classroom. New York, Routledge, 2016. 
Heble, Ajay and Rebecca Caines, Eds. The Improvisation Studies Reader: Spontaneous Acts. London, Routledge, 2015.

Hentoff, N. “How Jazz Helps Doctors Listen." Jazz Times, 2009, pp. 1-5.

Hisama, E. M. "Improvisation in Freestyle Rap." In The Oxford Handbook of Critical Studies in Improvisation Vol. 2, edited by G.E. Lewis and B. Piekut, Oxford University Press, 2016, pp. 250-57.

Hoffmann-Longtin, K. et al. "Twelve Tips for Using Applied Improvisation in Medical Education." Medical Teacher, vol. 40, 2018, pp. 351-56.

Hull, K. "Practicing Improvisation: Preparing Multicultural Educators." Multicultural Learning and Teaching, edited by Festus Obiakor and Robert Algozzine, vol. 10, 2015, pp. 183-96.

Ingram, P., and W. Duggan "Improvisation in Management." In The Oxford Handbook of Critical Studies in Improvisation Vol. 1, edited by G.E. Lewis and B. Piekut, Oxford University Press, 2016, pp. 385-95.

Johnstone, K. Impro: Improvisation and the Theatre, London, Methuen Drama, 2009.

Kagan, P. “Ave Atque Vale.” The New Criterion, vol. 99, 2013, pp. 1-34.

Koestler, A. The Act of Creation. Arkana/Penguin, 1964.

Kraft, U. "Unleashing Creativity." Scientific American Mind, 2005, pp. 16-23.

Laver, M. "Improvise! ${ }^{\mathrm{TM}}$. Jazz Consultancy and the Aesthetics of Neoliberalism." Critical Studies in Improvisation / Études Critiques en Improvisation, vol. 9, 2014.

LEAP. "What Is a 21st Century Liberal Education?" Association of American Colleges and Universities, 2016, www.aacu.org/leap/what-is-a-liberal-education.

Lewis, G. E., and B. Piekut. The Oxford Handbook of Critical Improvisation Studies, Vol. 1 and 2. Oxford, Oxford University Press, 2016.

Limb, C. J., and A. R. Braun. "Neural Substrates of Spontaneous Musical Performance: An FMRI Study of Jazz Improvisation." PLOS ONE, vol. 3, no. 2, doi:10.1371/journal.pone.0001679.

Liu, S., M.G. Erkkinen, et al. "Brain Activity and Connectivity during Poetry Composition: Toward a Multidimensional Model of the Creative Process." Human Brain Mapping, vol. 36, 2015, pp. 3351-3372.

Liu, S., H. M. Chow, et al. "Neural Correlates of Lyrical Improvisation: An fMRI Study of Freestyle Rap." Scientific Reports, vol. 2, 2012, pp. 1-8.

Magerko, B., and M. O. Riedl. "What Happens Next?: Toward an Empirical Investigation of Improv Theatre." Proceedings of the International Joint Workshop on Computational Creativity 2008 (5th IJWCC 2008), 2008, pp. 151-56. 
McNutt, Mark. I. "There Is Value in Liberal Arts Education, Employers Say." U.S. News \& World Report, 2014, www.usnews.com/news/college-of-tomorrow/articles/2014/09/22/there-isvalue-in-liberal-arts-education-employers-say.

McPherson, M. J., F. S. Barrett, et al. "Emotional Intent Modulates The Neural Substrates Of Creativity: An fMRI Study of Emotionally Targeted Improvisation in Jazz Musicians." Scientific Reports, vol. 6, 2016, pp. 1-14.

McPherson, M., and C. J. Limb. "Difficulties in the Neuroscience of Creativity: Jazz Improvisation and the Scientific Method." Annals of the New York Academy of Sciences, vol. 1303, 2013, pp. 80-83.

Montanaro, T., and K. Montanaro. Mime Spoken Here: The Performer's Portable Workshop. Montanaro and Montanaro, 1995.

Moyer, M., and M. Wenner. "The Serious Need for Play." Scientific American, vol. 25, 2016, pp. 50-57, doi:10.1038/SCIENTIFICAMERICANKIDS0616-50.

Nachmanovitch, S. Free Play: Improvisation in Life and Art. New York, Tarcher, 1990.

Nakata, H., et al. "Characteristics of the Athletes' Brain: Evidence from Neurophysiology and Neuroimaging." Brain Research Reviews, vol. 62, 2010, pp. 197-211.

Nettl, B. "Landmarks in the Study of Improvisation: Perspectives from Ethnomusicology." In The Oxford Handbook of Critical Studies in Improvisation Vol. 2, edited by G. Lewis and B. Piekut, Oxford University Press, 2016, pp. 169-84.

---. "Thoughts on Improvisation: A Comparative Approach.” The Musical Quarterly, vol. 60, 1974, pp. 1-19.

Pinho, A. L., et al. "Connecting to Create: Expertise in Musical Improvisation Is Associated with Increased Functional Connectivity between Premotor and Prefrontal Areas." The Journal of Neuroscience, vol. 34, 2014, pp. 6156-63.

Piper, T. "The Improvisational Flavour of Law, the Legal Taste of Improvisation." Critical Studies in Improvisation/ Études Critiques En Improvisation, vol. 6, 2010, pp. 1-5.

Pressing, J. "Improvisation: Methods and Models." In Generative Proceses in Music: The Psychology of Performance, Improvisation and Composition, edited by J. Sloboda, Oxford, 2001, pp. 130-78.

Prince, M. "Does Active Learning Work? A Review of the Research." Journal of Engineering Education., vol. 93, 2004, pp. 223-31.

Rothenberg, D. "Interspecies Improvisation." The Oxford Hanbook of Critical Studies in Improvisation Vol. 1, edited by G.E. Lewis and B. Piekut, Oxford University Press, 2016, pp. 500-22.

Saggar, M., et al. "Pictionary-Based fMRI Paradigm to Study the Neural Correlates of Spontaneous Improvisation and Figural Creativity." Scientific Reports, vol. 5, 2015, p. 10894. 
Sarath, E. Improvisation, Creativity, and Consciousness : Jazz as Integral Template for Music, Education, and Society. New York, State University of New York Press, 2013.

Sawyer, R. K. Creating Conversations : Improvisation in Everyday Discourse. New York, Hampton Press, 2001.

---. "Improvisation and the Creative Process: Dewey, Collingwood, and the Aesthetics of Spontaneity." The Journal of Aesthetics and Art Criticism, vol. 58, 2000, pp. 149-61.

Shi, B., et al. "Different Brain Structures Associated with Artistic and Scientific Creativity: A Voxel-Based Morphometry Study." Scientific Reports, vol. 7, 2016, pp. 1-8.

Symonds, M. "5 Reasons A Liberal Arts Education Rocks." Forbes, 2015, www.forbes.com/sites/mattsymonds/2015/11/30/5-reasons-a-liberal-arts-educationrocks/\#14d92c694179.

The Five Colleges of Ohio. "Creative and Critical Thinking: Assessing the Foundations of a Liberal Arts Education.” The Teagle Foundation, 2009, pp. 1-105.

Watson, K. "Perspective: Serious Play: Teaching Medical Skills With Improvisational Theater Techniques." Academic Medicine, vol. 86, 2011, pp. 1260-65.

Weick, K. E. "Introductory Essay-Improvisation as a Mindset for Organizational Analysis." Organization Science, vol. 9, 1998, pp. 543-55. 